\title{
Hydrodynamics and mass transfer in a packed column: Case of toluene absorption with a viscous absorbent
}

\author{
Frederic Heymes ${ }^{\mathrm{a}}$, Peggy Manno Demoustier ${ }^{\mathrm{a}}$, Françoise Charbit ${ }^{\mathrm{b}}$, Jean Louis Fanlo ${ }^{\mathrm{a}}$, \\ Philippe Moulin ${ }^{\mathrm{b}, *}$ \\ ${ }^{\mathrm{a}}$ LGEI, Ecole des Mines d'Alès, 6 avenue de Clavières, Alès 30319, France \\ ${ }^{\mathrm{b}}$ LPPE-UMR 6181, Université Paul Cezanne, Batiment Laennec, Hall C, Europole de l'arbois, BP 80, Aix en Provence 13545, France
}

\begin{abstract}
Volatile organic compounds (VOCs) cause nuisance to humans and the environment. Recent legislation encourages industrialists to set up equipment for treating their VOC-loaded gaseous effluents. This piece of research studies the absorption process, using a viscous organic absorbent (di(2-ethylhexyl) adipate = DEHA) to treat a toluene-loaded vent gas, in terms of hydrodynamics and mass transfer. It is shown that DEHA does not lead to an excessive pressure drop. Correlations predicting hydrodynamic parameters from previous literature are summarised and tested against experimental results. It is shown that acceptable prediction accuracy can be achieved for counter-current pressure drop and liquid hold-up. Treatment efficiency for the toluene-loaded vent gas is shown to be very good. Calculation of mass transfer constants $\left(k_{L} a\right)$ enables to test literature correlations against the experimental results. The mass transfer is supposed to be limited by the liquid-side resistance. Our experimental results showed that the $k_{L} a$ of the system depends on the liquid velocity but also on the gas velocity. This behaviour has also been observed by the few authors who have used viscous fluids in their experiments, but is contrary to all the authors who have work on low-viscosity fluids. It is therefore clear that the influence of viscosity on the phenomenon is considerable. Not one current correlation is currently accurate in the case of a viscous absorbent.
\end{abstract}

Keywords: Absorption; Hydrodynamics; Mass transfer; Environment; Chemical processes

\section{Introduction}

Atmospheric volatile organic compounds (VOCs) are involved in photochemical reactions that create ground-level ozone (urban smog) and entail environmental threats such as global warming, acid rain and air-borne toxics. In order to reduce anthropic emissions, legislation such as the Clean Air Act Amendments (1990) and EEC Directives (1999, 2001) specify maximum concentration levels for industrial emissions into the atmosphere. Various processes are available for VOC abatement, such as thermal or catalytic oxidation, adsorption, condensation, absorption, membrane permeation and biological treatments. No single method can be used in all cases: most of them are very specific in nature.

\footnotetext{
* Corresponding author. Tel.: +33442908505; fax: +33442908515.

E-mail address: philippe.moulin@univ.u-3mrs.fr (P. Moulin).
}

This paper focuses on the absorption method. The most important point concerning this process is the choice of a suitable absorbent liquid. In the case of hydrophobic VOCs, water cannot be used therefore other kinds of absorbents are required: water-oil emulsions, water-solid suspensions or liquids with high boiling points. Several authors studied the possibility of using such absorbents for industrial air cleaning processes. For toluene absorption, experiments carried out in a bubbling device (Heymes et al., 2006) have shown that di(2-ethylhexyl) adipate (DEHA) seems to be an efficient absorbent due to its good toluene affinity, acceptable viscosity, high diffusion coefficient, low vapour pressure, and because it is non-toxic, nonexplosive and inexpensive (Table 1).

However, viscosity of DEHA is more than 10 times greater than that in case of water $\left(14.4 \mathrm{mPa}\right.$ s at $\left.20^{\circ} \mathrm{C}\right)$. This point is a major concern, since viscosity plays an important role in hydrodynamics and mass transfer kinetics of an absorption tower. 
Table 1

Properties of pure DEHA and DEHA/toluene mixtures

\begin{tabular}{|c|c|c|c|}
\hline \multicolumn{2}{|l|}{ Pure DEHA properties } & \multicolumn{2}{|l|}{ Toluene/DEHA binary mixture } \\
\hline Formula & $\mathrm{C}_{22} \mathrm{H}_{42} \mathrm{O}_{4}$ & & \\
\hline Molar weight & $350.8 \mathrm{~g} \mathrm{~mol}^{-1}$ & Activity coefficient $(\gamma) 25^{\circ} \mathrm{C}$ & 0.50 \\
\hline Density & $930 \mathrm{~kg} \mathrm{~m}^{-3}$ & Henry's law constant $(H) 25^{\circ} \mathrm{C}$ & $1.98 \mathrm{kPa}$ \\
\hline Fusion temperature & $-76^{\circ} \mathrm{C}$ & Viscosity $\left(20^{\circ} \mathrm{C}\right)$ & $12.5 \mathrm{mPa} \mathrm{s}$ \\
\hline Vaporisation temperature & $210^{\circ} \mathrm{C}$ & & $8.65 \times 10^{-10}$ \\
\hline Vapour pressure $\left(20^{\circ} \mathrm{C}\right)$ & $3.25 \times 10^{-6} \mathrm{~Pa}$ & $\begin{array}{l}\text { Diffusion coefficient of toluene } \\
\text { in DEHA at infinite dilution }\left(25^{\circ} \mathrm{C}\right)\end{array}$ & $\mathrm{m}^{2} \mathrm{~s}^{-1}$ \\
\hline Cost & $<3 € \mathrm{~L}^{-1}$ & & \\
\hline
\end{tabular}

The first part of this work studies hydrodynamics (pressure drop, liquid hold-up and flooding point) of counter-current operation. The influences of gas and liquid flow rates are evaluated. Correlations from previous literature are summarised and tested against our results.

The second part studies toluene removal performance and mass transfer kinetics for DEHA flowing in a closed loop. Overall mass transfer constants $K_{L} a$ and $K_{G} a$ are calculated and presented. It is shown that there is a lack of knowledge about predicting transfer constants exists in case of a viscous absorbent.

\section{Theoretical considerations}

\subsection{Hydrodynamics of a counter-current gas-liquid flow in a packed column}

Optimising the operation of a packed column gas absorption system requires a thorough understanding of hydrodynamic parameters (pressure drop and liquid hold-up), which depend on many variables such as the flow rates and characteristics of the moving fluids under the operating conditions (temperature, pressure, physico-chemical properties) together with the type of column packing (size, shape, porosity). A very large number of studies have provided, in different cases, either semitheoretical or totally empirical relationships.

Various authors have tried to explain the experimental results by a phenomenological approach. Indeed, three different hydrodynamic regimes can be observed in the counter-current flow: (i) below the loading point, where gas and liquid flow without noticeable interaction (the liquid hold-up is independent of the gas velocity); (ii) the loading zone, where the shear stress between gas and liquid increases first slowly then much faster until the flooding point is reached (the liquid hold-up increases with the gas flow rate) and (iii) the flooding point which corresponds to a critical hydrodynamic state when, at a given liquid throughput, the gas flow rate becomes high enough to trigger liquid overflow from the column.

From an industrial point of view, it is of interest to predict the pressure drop per unit of height $\Delta P / Z\left(\mathrm{~Pa} \mathrm{~m}^{-1}\right)$ and the total liquid hold-up $h_{L}$ (simply referred to as the liquid hold-up) whatever the hydrodynamic regime is. Moreover, it is important to calculate the flooding point (defined by the values of the gas velocity at flooding point $U_{G, F}$ for each liquid velocity $U_{L}$ ) which should not be reached during normal operation.
Numerous attempts were made to model hydrodynamics by means of dimensionless parameters taking into account the properties of the system together with the gas and liquid flow rates. These relationships are indispensable for scaling the column and fluid flow apparatus in industrial processes. Table 2 summarises a non-exhaustive list of recent works on hydrodynamics in packed columns. All authors constituted a large data set of several thousands experimental points and most of them included viscous absorbents (engine oil, etc.). Previous systematic evaluations of the several correlations reached the conclusion that the Billet (1990) and Billet and Schultes (1991, 1992, 1995), the Mackowiak (1990, 1991) and the generalised pressure drop correlation (GPDC) (Leva, 1992) are recommended for predicting hydrodynamics in randomly packed columns providing the packing constants (packing factor). If packing constants are not available, the Miyahara correlation (1992) can be used. The statistical method of Piché et al. (2001) is a recent alternative to predict hydrodynamics in a packed column. Piché et al. used artificial neural networks and dimensional analysis (ANN-DA) to model both hydrodynamics and mass transfer in case of counter-current flows, with the advantage of not requiring any packing constant.

By comparing the accuracy of the different correlations, it appears that the Piché and Billet correlations forecast the loading and flooding points, pressure drop and liquid hold-up with a precision higher than 20\% (Piché et al., 2001). The Mackowiak formula presents a prediction accuracy of $20 \%$ on his data set whereas Miyahara obtains a precision of $30 \%$ with his data. The GPDC is accurate in the case of aqueous solutions but deviates for non-aqueous systems (average absolute error of $60 \%$ ). In order to give recommendations for industrialists interested in air treatment with high boiling point oil, it seemed relevant to compare the prediction accuracy of the Takahashi and Miyahara, Billet and Mackowiak correlations on our measurements. The neural correlation of Piché was not investigated because of the required and non-published weights of the neural network. The GPDC was not tested.

\subsubsection{The work of Takahashi et al. (1979) and Miyahara et al. (1992)}

The correlations of Miyahara and Takahashi are summarised in Table 3. The method of Zenz and Eckert is used to predict flooding and loading points with a single experimental constant $\alpha$. For the loading point, Miyahara gives $\alpha=0.547$; for the 
Table 2

Literature review about hydrodynamics in a packed column

\begin{tabular}{|c|c|c|c|}
\hline Year & Author & Predicted variables & Range of viscosity (mPas) \\
\hline 2003 & Iliuta et al. (2003) & Pressure drop, liquid hold-up, wetted area & $\approx 1$ \\
\hline 2001 & Piché et al. & Pressure drop, liquid hold-up, flooding point, wetted area & $0.09-50$ \\
\hline 1993 & Billet et al. & Pressure drop, liquid hold-up & $0.26-185$ \\
\hline 1992 & Leva & Pressure drop, flooding point & $0.2-20$ \\
\hline 1992 & Miyahara et al. & Pressure drop, liquid hold-up & $1.0-17.0$ \\
\hline 1991 & Mackowiak et al. & Pressure drop, liquid hold-up, flooding point & $0.2-8$ \\
\hline
\end{tabular}

Table 3

Formulae of Miyahara and Takahashi

Flooding and loading points

$$
\begin{aligned}
& X^{0.5}+Y^{0.5}=\alpha \text { with } \\
& X=U_{L, F} \sqrt{P_{x} S} \text { and } Y=U_{G, F} \sqrt{P_{y} S} \\
& \text { and } \\
& P_{X}=\frac{\mu_{L}^{0,2}}{g} \quad P_{y}=\frac{\rho_{G}}{\rho_{L}} \frac{\mu_{L}^{0,2}}{g} \quad S=\frac{a}{\varepsilon^{3}} \\
& h_{L}=\frac{1.53 \times 10^{-4}}{d_{p}^{1 . .2}}+1.42 \times 10^{-5} \varepsilon^{0.66}\left(\frac{\mu_{L}}{\mu_{\mathrm{H}_{2} \mathrm{O}}}\right)^{0.75} d_{p}^{-1.2} \\
& \quad+4.11 \times 10^{1}\left(\frac{Z}{d_{p}}\right)^{-0.35}{C a^{0.8}}^{-0.16} \mathrm{Fr}_{G}
\end{aligned}
$$

Pressure drop

$$
\begin{aligned}
& \text { Miyahara: } \frac{\Delta P}{Z}=\frac{\Delta P_{0}}{Z}+\beta \rho_{L} g h_{L} \\
& \text { Takahashi: } \frac{\Delta P}{Z}=\frac{\Delta P_{0}}{Z}+k h_{L}^{3}\left(\frac{U_{G}}{\varepsilon-h_{L}}\right)^{2}
\end{aligned}
$$

flooding point Miyahara gives $\alpha=0.629$ whereas Takashi suggests $\alpha=0.552$. The liquid retention is divided into three contributions (static hold-up, dynamic hold-up and operating dynamic hold-up). The pressure drop in counter-current flow is deduced from the liquid retention by adding the dry pressure drop to the wet pressure drop. Miyahara and Takahashi do not suggest the same model for the dry pressure drop: Miyahara considers that the wet pressure drop is proportional to the liquid retention whereas Takashi considers the pressure drop as a function of $h_{L}^{3} /\left(\varepsilon-h_{L}\right)^{2}$. Both require an experimental constant $k$ or $\beta$.

\subsubsection{The work of Billet (1990) and Billet and Schultes (1991, 1992, 1995)}

Billet starts from phenomenological observations to develop his theory (Table 4). He does not differentiate between static and dynamic hold-up and models directly the total liquid holdup by dissociating the behaviour of the column according to the operating zones and the liquid flow regime (Reynolds number). Before the loading point, Billet considers the liquid hold-up as a function of the liquid velocity and the hydraulic surface $a_{h}$. This surface is calculated by considering inertia, viscosity and gravity forces acting on the liquid. A packing parameter $C_{h}$ is required and is available in the literature or it can be calculated from simple experiments. Billet considers that the liquid holdup in the loading zone follows a polynomial behaviour versus gas velocity, with boundary conditions corresponding to the flooding point and the flow without gas. He showed that the polynomial is a 13 degree equation. Billet then calculates the total pressure drop by estimating the ratio of the wet column pressure drop $(\Delta P)$ over the dry column pressure drop $\left(\Delta P_{0}\right)$. This ratio depends on the hydrodynamic liquid flow represented by the parameter $f(S)$ and by the interaction between gas and liquid represented by the $\varepsilon /\left(\varepsilon-h_{L}\right)$ term.

\subsubsection{The work of Mackowiak (1990, 1991)}

Mackowiak uses a model of bed of suspended drops to predict the velocity of the gas at the flooding point (Table 5). The model consists of two linked equations enabling to calculate both the flooding gas velocity and flooding liquid hold-up. Liquid hold-up before the loading point depends on its velocity and enables the calculation of the liquid hold-up in the loading zone by a polynomial function of the gas velocity. Pressure drop can be calculated from the liquid hold-up by way of a drag coefficient $\Psi_{G, L}$ which depends on the liquid Reynolds number. Mackowiak's theory requires a flooding factor $C_{F l}$ and a packing shape factor $\mu_{M}$. The author gives many values for $C_{F l}$ and $\mu_{M}$ according to the packing used. 
Table 4

Formulae of Billet and Schultes

Liquid retention before loading point $\quad h_{L, S}=\left(\frac{12 \mu_{L} U_{L} a^{2}}{g \rho_{L}}\right)^{1 / 3}\left(\frac{a_{h}}{a}\right)^{2 / 3}$

where

$\frac{a_{h}}{a}=C_{h} \operatorname{Re}_{L}^{0.15} \operatorname{Fr}_{L}^{0.1} \quad$ if $\operatorname{Re}_{L}<5$

and

$\frac{a_{h}}{a}=0.85 C_{h} \operatorname{Re}_{L}^{0.25} \operatorname{Fr}_{L}^{0.1}$ if $\operatorname{Re}_{L} \geqslant 5$

$h_{L, F}=2.2 h_{L, S}\left(\frac{\mu_{L} \rho_{\mathrm{H}_{2} \mathrm{O}}}{\mu_{\mathrm{H}_{2} \mathrm{O}} \rho_{L}}\right)^{0.05}$

Liquid retention at flooding point

$h_{L}=h_{L, S}+\left(h_{L, F}-h_{L, S}\right)\left(\frac{U_{G}}{U_{G, F}}\right)^{n}$

Liquid retention at loading zone

$\frac{\Delta P}{\Delta P_{0}}=f_{B}\left(\frac{\varepsilon}{\varepsilon-h_{L}}\right)^{1,5}$ where $f_{B}=\exp \left(\frac{R e_{L}}{200}\right)$

Pressure drop before loading point

$\frac{\Delta P}{\Delta P_{0}}=f_{B}\left(\frac{\varepsilon}{\varepsilon-h_{L}}\right)^{1,5}$ where $f_{B}=\left(\frac{h_{L}}{h_{L, S}}\right)^{0,3} \exp \left(\frac{R e_{L}}{200}\right)$

Table 5

Formulae of Mackowiak

Flooding point

$U_{G, F}=C_{F l} \varepsilon^{1.2}\left(\frac{d_{h}}{d_{T}}\right)^{1 / 4}\left(\frac{d_{T} \rho_{L} g}{\rho_{G}}\right)^{1 / 2}\left(1-\frac{h_{L, F}}{\varepsilon}\right)^{7 / 2}$

Liquid retention at flooding point

where $d_{T}=\sqrt{\frac{\sigma_{L}}{\left(\rho_{L}-\rho_{G}\right) g}}$

For $\operatorname{Re}_{L}>2 \quad h_{L, F}=\frac{\varepsilon}{0.4\left(1-\lambda_{0}\right)}\left[\left(1.44 \lambda_{0}^{2}+0.8 \lambda_{0}\left(1-\lambda_{0}\right)\right)^{2}-1.2 \lambda_{0}\right]$

For $\operatorname{Re}_{L}<2 \quad h_{L, F}=\frac{\varepsilon}{0.24\left(1-\lambda_{0}\right)}\left[\left(1.254 \lambda_{0}^{2}+0.48 \lambda_{0}\left(1-\lambda_{0}\right)\right)^{2}-1.12 \lambda_{0}\right]$

where $\lambda_{0}=\frac{U_{L}}{U_{G, F}}$

Liquid retention up to loading point $\quad h_{L, S}=2.2 \sqrt{B_{L}} \quad$ where $B_{L}=\left(\frac{\mu_{L}}{\rho_{L} g^{2}}\right)^{1 / 3} \frac{U_{L}}{\varepsilon^{3}} \frac{1-\varepsilon}{d_{p}}$

Loading zone

$h_{L}=h_{L, F}-\left(h_{L, F}-h_{L, S}\right)\left[1-\left(\frac{\left(F_{G} / F_{G, F}\right)-0.65}{0.35}\right)\right]^{1 / 2}$

Pressure drop

$$
\frac{\Delta P}{\Delta P_{0}}=\frac{\Psi_{G, L}}{\Psi}\left(1+\frac{h_{L}}{1-\varepsilon}\right)\left(1-\frac{h_{L}}{\varepsilon}\right)^{-3}
$$

\subsubsection{Conclusion}

The principal models available for predicting pressure drop and liquid hold-up were presented. While the parameters taken into account are similar, their formulations are completely different due to the initial assumptions and subsequent developments. Takahashi and Billet separately calculate step by step the different hydrodynamic parameters of interest (flooding point, liquid retention, pressure drop) while Mackowiak 
proposes a different approach where flooding point and liquid hold-up are calculated together according to a suspended droplet bed approach.

The different authors calculate the wet pressure drop from the dry pressure drop. Miyahara and Takahashi add a term reflecting the liquid hold-up effect on gas pressure drop. Billet and Mackowiak consider that the influence of liquid flow on the gas pressure drop can be represented by multiplying the dry pressure drop with corrective terms. More details about the different correlations were not described in this paper, but the references were listed.

\subsection{Mass transfer in a counter-current flow}

Delaloye (1991) published a summary of the work carried out in the modelling of mass transfer coefficients. It appears that even the most recent of the studies listed date from more than 20 years ago and the authors devoted their efforts to systems whose viscosity is close to that of water ( $1 \mathrm{mPas})$. Delaloye (1991) highlights the inaccuracy of all these correlations as soon as the viscosity exceeds $10 \mathrm{mPa}$. DEHA, which is used in this study, is therefore outside the previously researched domains. Since this work, only Billet and Schultes $(1993,1999)$ has endeavoured to improve the modelling of the mass transfer coefficients, and he did not focus his work on viscous fluids. Two approaches will be presented and tested in this paper: one is old but much used: Onda, whereas the other is that of Billet.

\subsubsection{The Onda model (1968)}

This is the model most commonly used for predicting the surface area of interfacial exchange and the mass transfer constants for both gas and liquid. It introduces the distinction between the total surface area provided by the packing and the surface area actually wetted by the liquid, which is where the mass transfer takes place. This wetted surface area $a_{\text {wet }}$ is a function of the flow rate and the properties of the liquid and the packing. Onda proposes the equation:

$\frac{a_{\mathrm{wet}}}{a}=1-\exp \left(-1.45\left(\frac{\sigma_{c}}{\sigma_{L}}\right)^{0.75} \operatorname{Re}_{L}^{0.1} \mathrm{Fr}_{L}^{-0.05} W e_{L}^{0.2}\right)$.

$R e, F r$ and $W e$ are the dimensionless numbers of Reynolds, Froude and Weber. The formula considers the ratio of packing and liquid surface tensions $\sigma_{c} / \sigma_{L}$. The local transfer coefficients for the liquid $\left(k_{L}\right)$ and gas $\left(k_{G}\right)$ are then calculated from the following relationships giving the Sherwood numbers:

$S h_{L}=0.0051 R e_{L, \text { wet }}^{4 / 3} S c_{L}^{-1 / 2}\left(a d_{p}\right)^{0.4}$,

$S h_{G}=5.23 \operatorname{Re}_{G, \text { wet }}^{0.7} S c_{G}^{1 / 3}\left(a d_{p}\right)^{-2.0}$.

\subsection{The Billet model (1993, 1999)}

Billet et al. developed a model enabling mass transfer coefficients to be determined for both the gas and the liquid. The proposed correlations were established from a bank of experimental results containing more than 3500 sets of data, measured under the conditions of 46 different systems. The equations define and take into account the interfacial area actually involved in the transfer:

$$
\begin{aligned}
\frac{a_{\text {wet }}}{a}= & 1.5\left(a d_{h}\right)^{-0.5} \operatorname{Re}_{L}^{-0.2} W_{L}^{0.75} \mathrm{Fr}_{L}^{-0.45}, \\
k_{L} a_{\mathrm{wet}}= & C_{L}^{*}\left(\frac{\rho_{G} g}{\mu_{G}}\right)^{1 / 6}\left(\frac{D_{L}}{d_{h}}\right)^{1 / 2} a^{2 / 3} U_{L}^{1 / 3}\left(\frac{a_{\mathrm{wet}}}{a}\right), \\
k_{G} a_{\mathrm{wet}}= & C_{G}^{*} \frac{1}{\left(\varepsilon-h_{T}\right)^{1 / 2}} \frac{a^{3 / 2}}{d_{h}^{1 / 2}} D_{G}\left(\frac{U_{G} \rho_{G}}{a \mu_{G}}\right)^{3 / 4} \\
& \times\left(\frac{\mu_{G}}{\rho_{G} D_{G}}\right)^{1 / 3}\left(\frac{a_{\mathrm{wet}}}{a}\right) .
\end{aligned}
$$

$C_{L}^{*}, C_{V}^{*}$ are experimental constants of the Billet equations. Billet proposes the values $C_{L}^{*}=1.577$ and $C_{V}^{*}=0.390$ for Hiflow rings of a nominal diameter of $25 \mathrm{~mm}$.

The approaches of these authors are similar in terms of modelling. They correlate the real wetted interfacial area $a_{\text {wet }}$ with the physico-chemical properties of the system and deduce the mass transfer coefficients for the gas from the velocity of the gas and the mass transfer coefficients of the liquid from the velocity of the liquid. Only the forms of the equations differ.

\section{Materials and methods}

Hydrodynamics and mass transfer experiments were performed with di(2-ethylhexyl) adipate supplied by BASF.

\subsection{Hydrodynamics}

Fig. 1 shows the pilot unit used for this study. It is made of Schott glassware parts. The column has an internal diameter

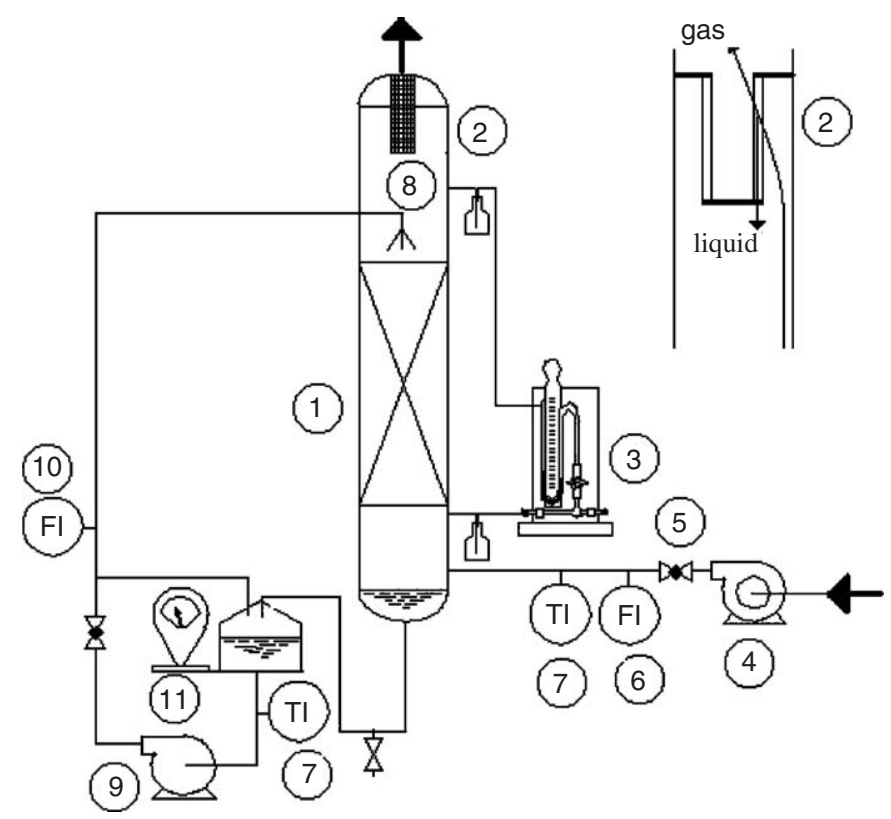

Fig. 1. Flow sheet of hydrodynamics experimental setup. 


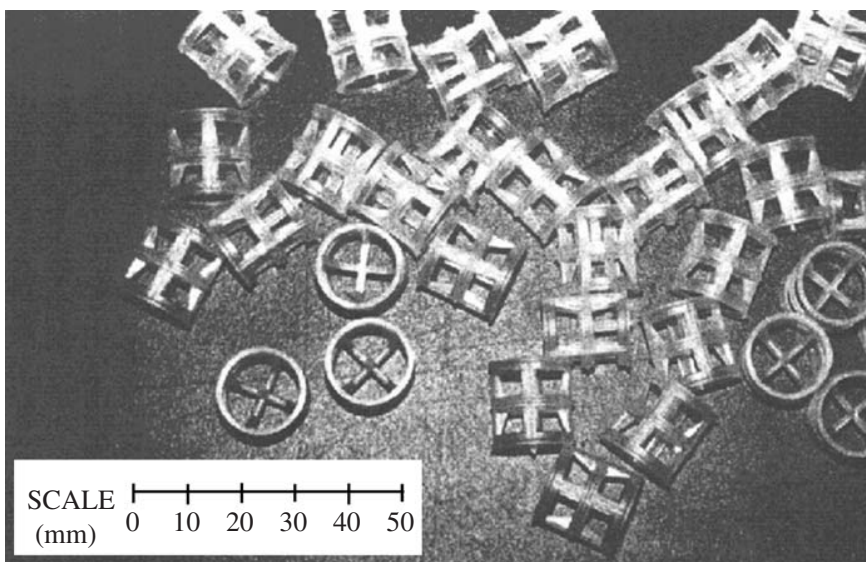

Fig. 2. Hiflow rings.

of $D=0.1 \mathrm{~m}$ and a total height of $2.5 \mathrm{~m}$. The packing (1) consists of a stack of Hiflow rings (Techim, France) to a height of $Z=1 \mathrm{~m}$. The Hiflow rings (Fig. 2) are made of polypropylene $\left(\sigma_{c}=0.03 \mathrm{~N} \mathrm{~m}^{-1}\right)$ wires and are a highly porous type of packing (void fraction $\varepsilon=0.92$ ). Because of this high porosity, Hiflow rings are suitable for high gas flow rates and are therefore well suited for the treatment of industrial gaseous effluents. The particle diameter is $d_{p}=17 \mathrm{~mm}$ and the specific area is $a=$ $275 \mathrm{~m}^{2} \mathrm{~m}^{-3}$. The ratio $D / d_{p}$ equals 5.9 , but according to Baker this ratio is not sufficient and wall flow could occur. However, such an effect was not observed experimentally. The packing was held in place top and bottom by grids whose porosity was close to $100 \%$.

The column was topped with a droplet collector (2) fabricated in the laboratory. This device was made of many grid layers in a cylindrical shape collecting the droplets. Two pressure taps situated under and over the retainer grids enabled the pressure drop created by the packing to be measured. These two taps were connected to a vertical U-shaped tube filled with water (3). The apparatus was fed with air by means of a $1.5 \mathrm{~kW}$ fan (4) (LAFERT, France). The maximum load was $2.8 \mathrm{~m}$ of water and the maximum flow rate $180 \mathrm{~m}^{3} \mathrm{~h}^{-1}$. The air flow was regulated by means of a butterfly valve (5) placed after the fan. The velocity was measured using a hot-wire anemometer (Kimo, France). The temperatures of the gas and liquid (7) were measured by means of a thermocouple (Kimo, France). The column was fed with washing liquid through a conical sprinkler (8) by means of a centrifugal pump (SALMSON $700 \mathrm{~W}$, France) with a maximum of flow of $3.6 \mathrm{~m}^{3} \mathrm{~h}^{-1}$ and a maximum load of $38 \mathrm{~m}$ water. The flow rate through the column was regulated by means of two valves situated on the recirculation by-pass and the column input. The liquid flow rate was measured using a water-meter type volumetric counter (10) (M2RSP-1H, Macnaught, Australia). A $10 \mathrm{~L}$ liquid reservoir was placed on a scale (Mettler PJ 6000, France) (11). The protocol for measuring the static hold-up was as follows: the initially dry packing was wet with the absorbent and after a sufficient lapse of time, the volume of undrained liquid corresponds to the static hold-up. The experimental procedure enabled simultaneous measurement of the pressure drop undergone by the gas current circulating alone or counter-current to the liquid, and the liquid hold-up in the column according to the following experimental protocol. The complete setup was filled with absorbent. The pump was stopped and, after a while, the mass of liquid on the balance (11) was measured. Then, the pump was switched on at a given flow rate. After stabilisation, the total hold-up was determined by the difference in weight: the missing liquid in the tank was held by the column. For each liquid flow rate, the gas flow was increased incrementally up to flooding point. At each incremental step, we waited until the hydrodynamic equilibrium was reached because the sudden increase in the gas flow perturbs the system, which then gradually returns to a state of the hydrodynamic equilibrium in which the liquid hold-up and pressure drop are constant. Experimental investigation at that point showed that waiting 5 min was sufficient to obtain stable and accurate data. The range of fluid flow rates was $L=2.9-9.8 \mathrm{~kg} \mathrm{~m}^{-2} \mathrm{~s}^{-1}$ and $G=0-3.5 \mathrm{~kg} \mathrm{~m}^{-2} \mathrm{~s}^{-1}$. Since the height of packing was $1 \mathrm{~m}, \Delta P / Z$ was directly read on the $\mathrm{U}$ tube and $h_{L}$ was calculated by dividing the missing volume of absorbent by the cross-section of the column.

The accuracy of the different correlations to assess our experimental results was evaluated by the statistical indicator average absolute relative error (AARE) defined as follows:

$\mathrm{AARE}=\frac{1}{n} \sum_{i=1}^{n} \frac{X^{\text {theory }}-X^{\text {experimental }}}{X^{\text {experimental }}}$ for $n$ data.

\subsection{Mass transfer}

The experimental apparatus is represented in Fig. 3. Toluenecharged gas was generated by means of a micrometric pump (3) which injected toluene into a current of compressed air (2). The mixture was pumped into a heated flask to ensure that the toluene was completely evaporated. The flow of polluted air was injected into the main air inlet current, whose flow rate was measured using a hot-wire anemometer (5). The mixed gas flow was homogenised by means of a static mixer $(L=1 \mathrm{~m})$ (Durapack, Schott, France) before being introduced into the column.

The aim was to study the mass transfer of toluene present in the gaseous phase to the DEHA. The setup operated in open loop for the gas and closed loop for the liquid. This implied that the concentration in the liquid was not constant at the inlet of the column. Sampling points for the liquid at the top and the bottom of the column (1) allowed determination of the toluene concentration in DEHA by means of a UV spectrometer (Secomam, France) at a wavelength of $\lambda=259.9 \mathrm{~nm}$. Air sample flows were pumped at the head and foot of the column and were analysed each second using a chromatograph (6, HP 5890). Results were averaged to obtain a point per minute.

A known volume of solvent was introduced into the thermostated balloon flask and moved through the by-pass by the centrifugal pump. The coil of water in the balloon flask balanced out the heat imparted to the fluid by the centrifugal pump so as to work at constant temperature $\left(20^{\circ} \mathrm{C}\right)$. The micrometric 

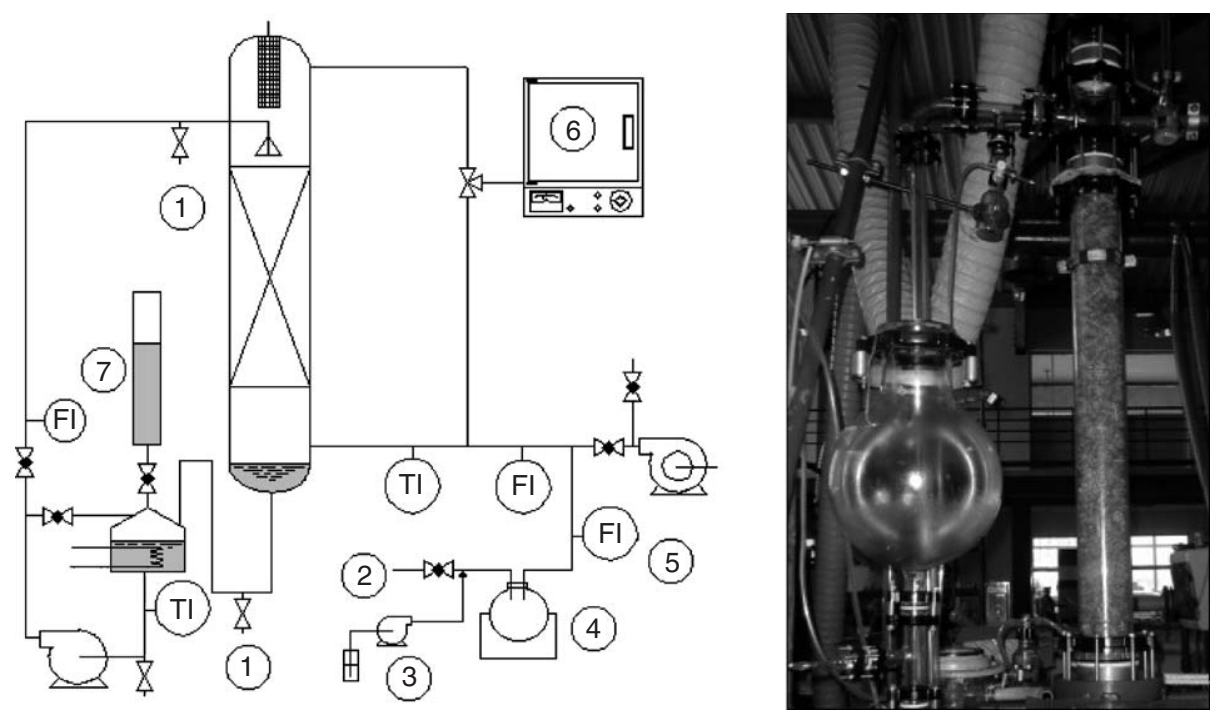

Fig. 3. Flow sheet and picture of mass transfer experimental setup.

pump was set to inject the correct amount of toluene for the desired air flow and concentration. The column outlet was monitored by means of FID to ensure that the toluene concentration in the gas was stable and equal to the desired value. Time $t=0$ corresponds to the opening of the valve to introduce the DEHA into the top of the column. The flow rate was quickly set to the desired value by means of this valve and that of the bypass. From that moment, the absorption started and the toluene concentration in the liquid rose little by little. The toluene concentration at the gas outlet fell quickly because of the absorption by the DEHA and rose after a while to its initial value when DEHA was not able to absorb any more toluene. Then the experiment was over. Experiments could last up to $40 \mathrm{~h}$. They were carried out in batches using $10 \mathrm{~L}$ of DEHA. The temperature of the DEHA was kept constant throughout the experiments. The temperature of the air varied between 22 and $31{ }^{\circ} \mathrm{C}$. This variation of the air temperature did not influence the absorption results since the liquid temperature was stable. The toluene concentrations and air and liquid flow rates tested were as follows:

(i) toluene concentrations in gas phase: 500; 1000; 5000 $\mathrm{mg} \mathrm{m}^{-3}$

(ii) liquid flow rates $L=6.58 ; 9.87 ; 13.16 \mathrm{~kg} \mathrm{~m}^{-2} \mathrm{~s}^{-1}$;

(iii) gas velocities: $0.42 ; 1 ; 1.5 \mathrm{~m} \mathrm{~s}^{-1}(G=0.51 ; 1.21$ and $\left.1.81 \mathrm{~kg} \mathrm{~m}^{-2} \mathrm{~s}^{-1}\right)$.

This corresponds to $L / G$ values ranging from 3.6 to 25.9 . The gas and liquid flow rates were chosen from the results of the hydrodynamic study in order to explore an interesting range of $L / G$ values. The values of the gas phase toluene concentration at the column outlet $C_{G, S}(t)$ were used at 1-min intervals in the following equations. The toluene removal performance is defined as $100 \times\left(C_{G \text {,in }}-C_{G \text {,out }}(t)\right) / C_{G \text {,in }}$. The mass balance in the column was verified by the equations:

$Q_{G}\left(C_{G, \text { in }}-C_{G, \text { out }}(t)\right)=Q_{L}\left(C_{L, \text { out }}(t)-C_{L, \text { in }}(t)\right)$,

$$
\begin{aligned}
& Q_{G}\left(C_{G, \text { in }}-C_{G, \text { out }}(t)\right) \\
& =K_{L} a V_{C} \frac{\left(C_{G, \text { in }} / H-C_{L, \text { out }}(t)\right)-\left(C_{G, \text { out }} / H-C_{L, \text { in }}(t)\right)}{\operatorname{Ln}\left(\frac{C_{G, \text { in }} / m-C_{L, \text { out }}(t)}{C_{G, \text { out }} / H-C_{L, \text { in }}(t)}\right)}, \\
& Q_{G}\left(C_{G, \text { in }}-C_{G, \text { out }}(t)\right) \\
& =K_{G} a V_{C} \frac{\left(C_{G, \text { in }}-H C_{L, \text { out }}(t)\right)-\left(C_{G, \text { out }}-H C_{L}, \text { in }(t)\right)}{\operatorname{Ln}\left(\left(C_{G, \text { in }}-H C_{L, \text { out }}(t)\right) /\left(C_{G, \text { out }}(t)-H C_{L, \text { in }}(t)\right)\right)} .
\end{aligned}
$$

Since the liquid flowed in a closed loop, the inlet liquid concentration varied with time. This unsteady state required a mathematical treatment of the experimental points to calculate $K_{L} a$ and $K_{G} a$ by linear regression. $H$ is the equilibrium constant (Henry's law constant) between the liquid and gas phases defined as $C_{G}=H C_{L}^{*}$.

\section{Results and discussion}

\subsection{Experimental results}

Experimental points at constant liquid flow rate are plotted in Fig. 4. Pressure drop [A] and liquid hold-up [B] are given in $\log -\log$ scale. Flooding data were determined and is indicated in the chart $[\mathrm{C}]$ included in Fig. 4. The experimental points for the pressure drop under the flooding point can be well represented by a line with a slope equal to 2.26 (corresponding to the exponent of the gas velocity). Concerning liquid hold-up, the resulting curves correspond to the classical behaviour, as described by Billet. The Mackowiak assumption, which states that the loading zone begins at $65 \%$ of the flooding point, is quite fairly respected.

Fig. 5 shows the experimental results for toluene recovery performance with three different gas flow rates. It appears that the ranges of flow rates and concentrations investigated give an initial toluene removal performance close to $100 \%$, 


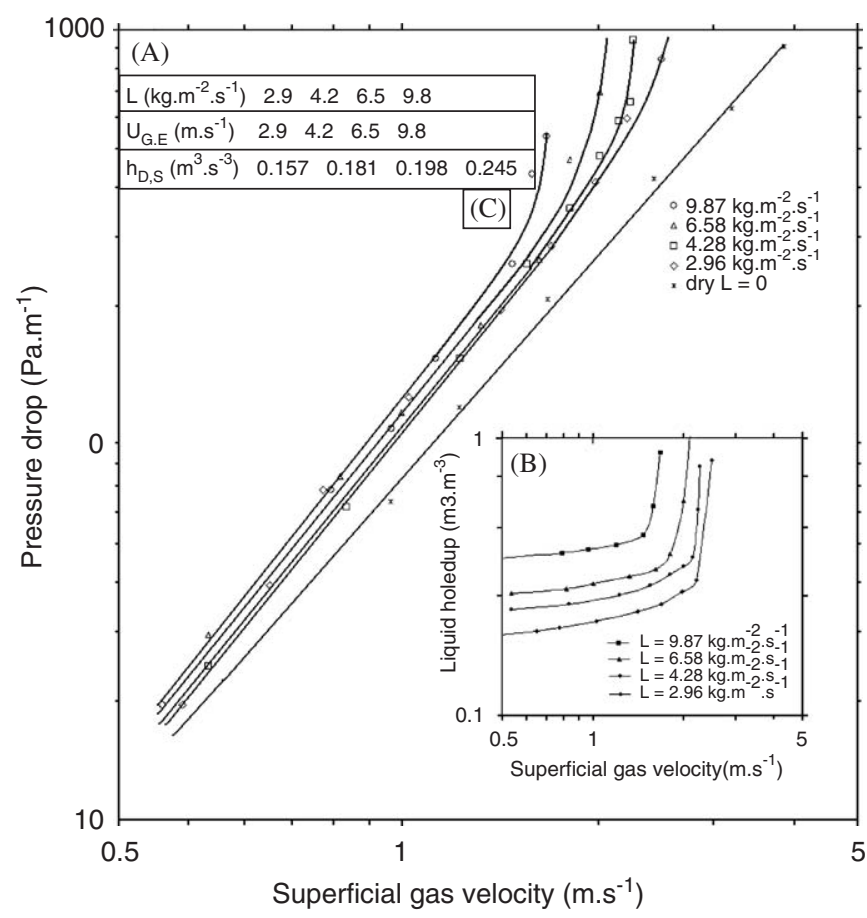

Fig. 4. Pressure drop, liquid hold-up and flooding points as a function of gas and liquid flow rates.

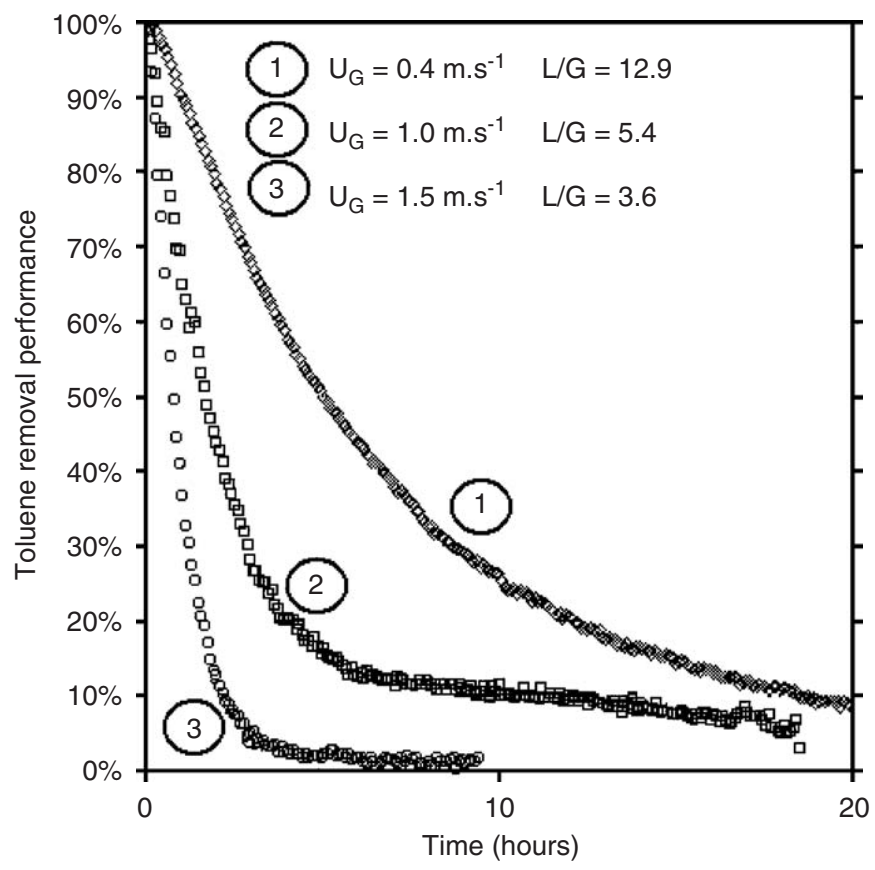

Fig. 5. Toluene removal performance as a function of time and gas superficial velocity $\left(L=6.58 \mathrm{~kg} \mathrm{~s}^{-1} \mathrm{~m}^{-2}\right)$.

whatever the configuration. This confirms the interest of DEHA as an efficient absorbent for treating a gas loaded with toluene, with concentrations varying between 500 and $5000 \mathrm{mg} \mathrm{m}^{-3}$. Nonetheless, this performance decreases very quickly when the liquid becomes enriched with toluene. Fig. 5 shows this drop in toluene removal according to the gas or liquid flow rates used. The influence of the gas and liquid flow rates versus time is very marked, depending on the $L / G$ ratio.

However, these qualitative results cannot be extrapolated. It is therefore necessary to calculate the gas and liquid transfer constants $K_{L} a$ and $K_{G} a$. For that purpose, it was necessary to calculate the Henry's law constant $H$ between the liquid and gas phases. Since all experiments were performed until the equilibrium state between the gas and liquid was reached, the equilibrium constant was determined by plotting $C_{G}$ versus $C_{L}^{*}$. It was found that $H=1.96 \times 10^{-6}$ at $20^{\circ} \mathrm{C}$. The values of the global mass transfer coefficients were then calculated using the method indicated previously and they are listed in Table 6.

\subsection{Discussion}

\subsubsection{Hydrodynamics}

The prediction of dry pressure drop is not presented here because of its low interest. The Ergun formula is accurate, but constants $h_{K}=1682$ and $h_{B}=1.665$ have to be used. Miyahara, Billet and Mackowiak formulae were tested with our experimental data. Very good accuracy was observed (3-5\%). For wet pressure drop and liquid hold-up, the correlations presented in the theoretical part of this paper were compared with our experimental results.

4.2.1.1. Miyahara and Takashi modelling. In flooding point prediction a significant error appeared when using Miyahara constants. The closest prediction of the flooding point is observed when the value of $\alpha$ is taken to be 0.69 . The AARE is then $1.5 \%$. This value is higher than those given by Miyahara and Takahashi (resp. $\alpha=0.629$ and $\alpha=0.552$ ) for the packing systems they used. This results from the fact that our system floods at higher gas and liquid flow rates, which confirms the favourable hydrodynamic behaviour of Hiflow rings.

Takahashi divides liquid hold-up into three terms: static, dynamic and operating dynamic liquid hold-up. Static hold-up is very poorly predicted, since the correlation gives a value $h_{s}=0.020 \mathrm{~m}^{3} \mathrm{~m}^{-3}$ while the experimental measurement is $0.008 \mathrm{~m}^{3} \mathrm{~m}^{-3}$. This is not surprising since Miyahara's formula does not take into account the surface tension and density of the liquid. Concerning the dynamic and operating hold-up, the predictions are more accurate. The relationship predicting the dynamic liquid hold-up has an AARE of $11 \%$, whereas the relationship predicting the operating liquid hold-up has an AARE of up to $22 \%$. The author did not specify the range of use, but it seems that the proposed correlation while simple to use, is not appropriate for high liquid flow rates. Concerning the pressure drop, Miyahara and Takahashi propose adding a liquid term to the dry pressure drop. The inaccuracy concerning the prediction of the operating liquid hold-up has an impact on the prediction of the wet pressure drop. Takahashi correlation is reasonably satisfactory $(\mathrm{AARE}=21 \%)$.

4.2.1.2. Billet modelling. The correlations proposed by Billet proved very accurate for predicting our results 
Table 6

Experimental overall mass transfer constants $K_{L} a$ and $K_{G} a$

\begin{tabular}{|c|c|c|c|c|c|}
\hline Experiment number & [toluene] $\left(\mathrm{mg} \mathrm{m}^{-3}\right)$ & $\mathrm{L}\left(\mathrm{kg} \mathrm{m}^{-2} \mathrm{~s}^{-1}\right)$ & $\mathrm{G}\left(\mathrm{kg} \mathrm{m}^{-2} \mathrm{~s}^{-1}\right)$ & $K_{L} a\left(\mathrm{~s}^{-1}\right)$ & $K_{G} a\left(\mathrm{~s}^{-1}\right)$ \\
\hline 1 & 4990 & 13.16 & 0.51 & $2.52 \times 10^{-4}$ & 2.75 \\
\hline 2 & 1205 & 13.16 & 0.51 & $2.51 \times 10^{-4}$ & 0.79 \\
\hline 3 & 1193 & 9.87 & 0.51 & $3.69 \times 10^{-4}$ & 1.89 \\
\hline 4 & 5038 & 6.58 & 0.51 & $3.23 \times 10^{-4}$ & 1.34 \\
\hline 5 & 520 & 6.58 & 1.16 & $2.28 \times 10^{-3}$ & 13.5 \\
\hline 6 & 1005 & 6.58 & 1.21 & $2.38 \times 10^{-3}$ & 13.8 \\
\hline 7 & 1005 & 6.58 & 1.81 & $2.43 \times 10^{-3}$ & 12.1 \\
\hline
\end{tabular}

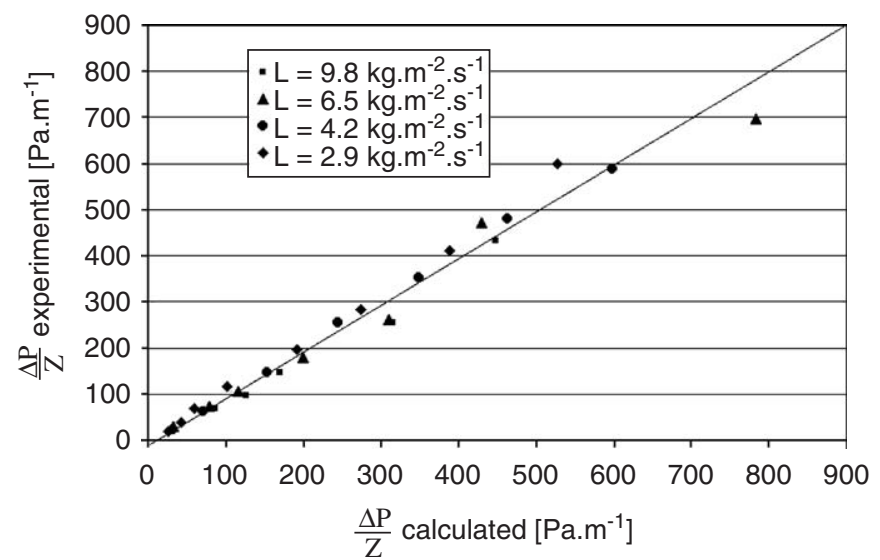

Fig. 6. Parity graph of Billet's formulae.

concerning the loading zone. In fact, Billet's correlation gives a satisfactory prediction for the liquid hold-up (AARE $=6 \%$ ). In the loading zone, a divergence was observed when the liquid flow rate increased (AARE from 5\% to $19 \%$ for liquid flow rates of $3.2 \times 10^{-3}$ to $10.6 \times 10^{-3}$, respectively). These divergences are mainly due to the zone close to the flooding point. Fig. 6 highlights the good predictions for pressure drops given by Billet's relation provided the system is not too close to flooding.

4.2.1.3. Mackowiak modelling. Iteration of the Mackowiak equations enables the calculation of the velocities and liquid hold-up at the flooding point. The most accurate predictions were obtained by taking a droplet diameter $d_{T}=2.5 \mathrm{~mm}$. The velocities at the flooding point were predicted at $4 \%$ and the liquid hold-up at $8 \%$. Concerning liquid hold-up at zero gas flow rate, Mackowiak's equation gives approximate results with the coefficient proposed by the author. A deviation of $37 \%$ was observed. By modifying the empirical coefficients in the correlation, an accuracy of $6 \%$ could be achieved. The new correlation for predicting the total dynamic hold-up at zero gas flow rate should be written as

$h_{L, S}=\underbrace{3.61}_{\text {modified value }} \sqrt{B_{L}}$ with $B_{L}=\left(\frac{\mu_{L}}{\rho_{L} g^{2}}\right)^{1 / 3} \frac{U_{L}}{\varepsilon^{2}} \frac{1-\varepsilon}{d_{p}}$.

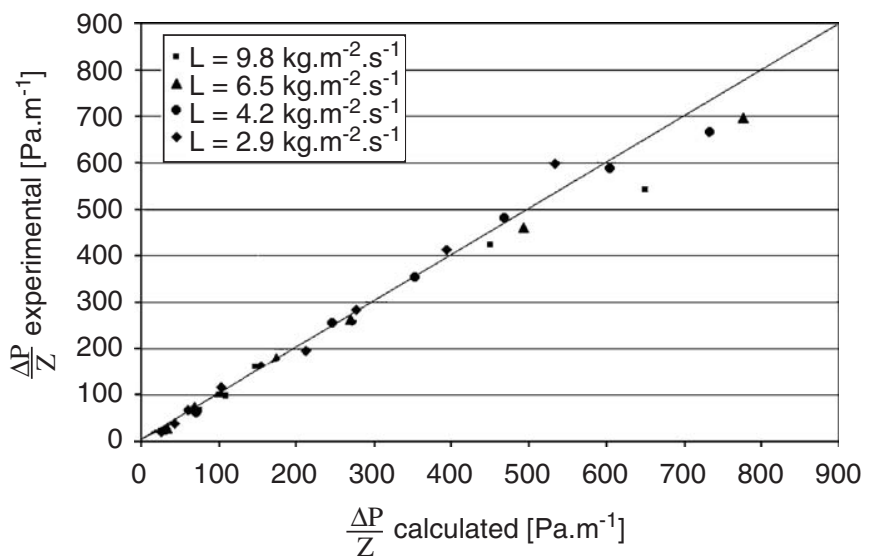

Fig. 7. Parity graph of Mackowiak's formulae.

Mackowiak's work enabled the total pressure drop to be estimated with an error of $15 \%$ (Fig. 7).

4.2.1.4. Influence of viscosity. The Miyahara, Billet and Mackowiak formulae presented good prediction accuracy. Our data can be completed with the work of Cotte (1996), who studied the hydrodynamics of air/water/Hiflow ring and air/PEG 400/Hiflow ring systems. All data could not be compared rigorously because of the different gas and liquid flow rates used by the author. Nonetheless, examining the whole set of values revealed similarity of the reported points (Table 7). The three experimental points correspond to the beginning of loading zone. As certain authors have observed (Billet and Schultes, 1991; Cotte, 1996), the viscosity of the liquid considerably influences the hydrodynamic behaviour of the column. Indeed, the viscosity of the three liquids varies by a factor of 80 . The Reynolds number was calculated according to the definition of Billet and Mackowiak.

Table 8 presents the predicted results of Billet and Mackowiak for liquid hold-up and pressure drop in comparison with experimental data. It is obvious that Billet's formulae predict results with a good accuracy (9\% in case of liquid hold-up, $18 \%$ in case of pressure drop). The Mackowiak formula gives bad predictions for liquid retention $(\mathrm{AARE}=54 \%)$ and pressure drop. With the modified constant, the result is better $(25 \%)$ but still insufficient to have an accurate prediction about pressure drop. This reveals that Mackowiak's formulae require a 
Table 7

Comparison of experimental data with literature

\begin{tabular}{|c|c|c|c|c|c|}
\hline Author & Liquid & $U_{G}\left(\mathrm{~m} \mathrm{~s}^{-1}\right)$ & $L\left(\mathrm{~kg} \mathrm{~m}^{-2} \mathrm{~s}^{-1}\right)$ & $\mu\left(25^{\circ} \mathrm{C}\right)(\mathrm{Pa} \mathrm{s})$ & $R e$ \\
\hline Cotte (1996) & Water & 1.0 & 4.2 & 0.0010 & 15 \\
\hline This work & DEHA & 1.0 & 4.2 & 0.0144 & 1.0 \\
\hline Cotte (1996) & PEG 400 & 1.0 & 3.9 & 0.0820 & 0.17 \\
\hline
\end{tabular}

Table 8

Comparison of Billet and Mackowiak predictions versus experimental results

\begin{tabular}{|c|c|c|c|c|c|c|c|}
\hline & \multicolumn{3}{|c|}{ Pressure drop $\left(\mathrm{Pa} \mathrm{m}^{-1}\right)$} & \multicolumn{4}{|c|}{ Liquid hold-up $\left(\mathrm{m}^{3} \mathrm{~m}^{-3}\right)$} \\
\hline & Experimental & Billet & Mackowiak & Experimental & Billet & Mackowiak & Mackowiak (modified) \\
\hline Water & 77 & 86 & 322 & 0.081 & 0.073 & 0.049 & 0.080 \\
\hline DEHA & 107 & 93 & 1257 & 0.197 & 0.186 & 0.080 & 0.131 \\
\hline PEG 400 & 150 & 105 & 2595 & 0.259 & 0.290 & 0.092 & 0.151 \\
\hline
\end{tabular}

new consideration in the case of viscous liquids. Billet's correlation gives accurate results, by considering Eqs. (4) and (10), it appears that Billet models the liquid hold-up with a power of viscosity equal to $0.267(R e<5)$ while Mackowiak proposes a power of viscosity equal to 0.16 . A regression on the results of the table gives a power of viscosity equal to 0.269 . The exponent proposed by Billet fits well with our data.

4.2.1.5. Conclusions about hydrodynamics. Experiments performed in a pilot scale setup revealed that using DEHA does not create excessive pressure drops. When comparing our results with experiments performed with water in the same column, it appears that the viscosity of DEHA creates a supplementary pressure drop lower than $30 \%$ of the water pressure drop. This pressure drop is acceptable for industrial purposes. Concerning modelling, the most significant recent works were studied and compared with our experimental results. The authors' excellent predictions for dry bed pressure drops (3-5\%) are worse when the column is wetted (20-25\%): this comes from the increased complexity of the triphasic gas-liquid-solid system. Both the old approach of Eckert, updated by Miyahara and the new approach of Mackowiak modelled the flooding points fairly well. Thus, the hydrodynamic point where this chaotic state occurs can be accurately predicted. However, if under and in the loading zone the hydrodynamic parameters $\left(\Delta P / Z\right.$ and $\left.h_{L}\right)$ are sufficiently predicted, when approaching the flooding point the error increases significantly. Overall results and observations about the influence of viscosity lead us to consider that Billet's correlations should be recommended for scaling industrial equipment. Results are accurate and the formulae are simpleto-use. The mass transfer in the column will now be considered.

\subsubsection{Mass transfer}

4.2.2.1. Air treatment performance considerations. Experimental results show that the toluene-charged vent gas can be cleaned efficiently (Fig. 5). The legal limit of toluene release into the atmosphere is $110 \mathrm{mg} \mathrm{m}^{-3}$ (EEC directive). This corresponds to removal performances of $78 \%, 89 \%$ and $98 \%$ according to the experimental concentrations $(500,1000$,
$5000 \mathrm{mg} \mathrm{m}^{-3}$ ). The experimental pilot used in this study could therefore fulfil the requirements to treat a small flow industrial vent gas. Since DEHA is a viscous liquid and that the Henry's law constant is not too high, it can be assumed that the main transfer resistance is located in the liquid phase. In fact, diffusion coefficients of toluene are $8.6 \times 10^{-6} \mathrm{~cm}^{2} \mathrm{~s}^{-1}$ in DEHA (Heymes, 2006) and $8.7 \times 10^{-2} \mathrm{~cm}^{2} \mathrm{~s}^{-1}$ in air. Values of $K_{L} a$ (Table 6) are low in comparison with literature data about classical mass transfer constants (up to $0.1 \mathrm{~m} \mathrm{~s}^{-1}$ ). This reflects the negative effect of viscosity on absorption kinetics, in particular on the diffusion coefficient and the liquid boundary layer thickness. Low values of $K_{L} a$ involve a high height of transfer units (HTU) increasing the necessary total height of an industrial column.

4.2.2.2. $k_{L}$ a considerations. Since the mass transfer resistance is mainly located in the liquid boundary layer, local liquid mass transfer constant $k_{L} a$ are equal to overall liquid mass transfer constant $K_{L} a$. A difference in order of a factor of 10 between the different values of $k_{L} a$ can be observed. To explain this observation, it is useful to link mass transfer to the hydrodynamics of the column. Fig. 8 is a development of the liquid hold-up curves presented in the hydrodynamics section. The zones representing the loading regime and flooding point of the column were added in grey. The hatched area corresponds to the range of operating conditions used for the mass transfer experiments. Experiments 1-7 have been added to the figure to show at a glance the differences in calculated $k_{L} a$ values depending on the hydrodynamic regime in the column. In fact, points 1-4, which are not located in the loading regime, have the lowest $k_{L} a$ values (around $10^{-4}$ ), while the points located in the loading zone have $k_{L} a$ values around $10^{-3}$. It is well-known that the loading zone corresponds to efficient hydrodynamic conditions which enhance mass transfer kinetics.

Experiments 1-4 were led with the same gas flow rate below the loading zone. Results show no significant influence of liquid flow rates on liquid mass transfer constants. The liquid hold-up rises from 0.20 to $0.30 \mathrm{~m}^{3} \mathrm{~m}^{-3}$ and the $k_{L} a$ from $2.5 \times 10^{-4}$ to $3.7 \times 10^{-4} \mathrm{~s}^{-1}$. This confirms that interactions between the 


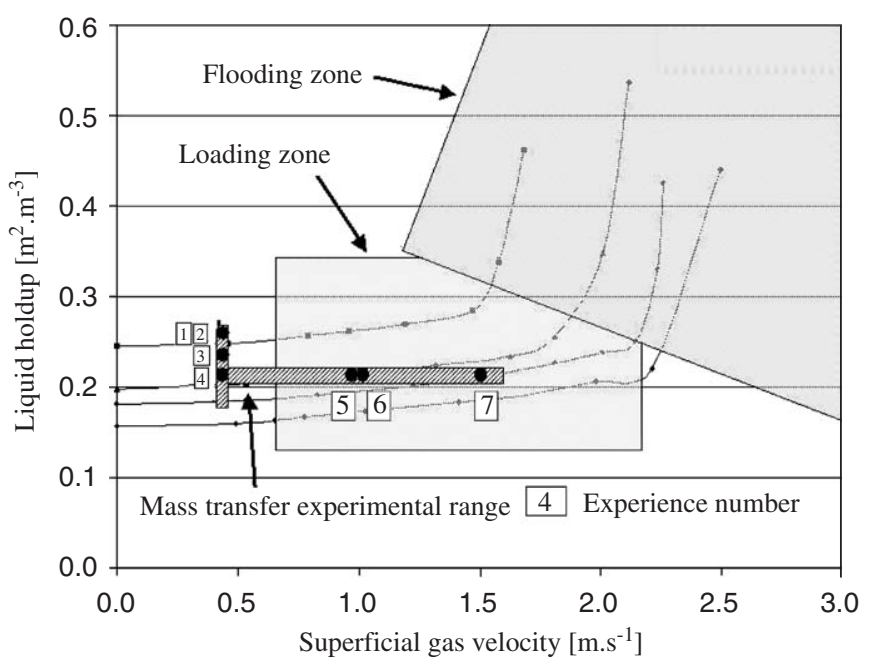

Fig. 8. Mass transfer experimental conditions and hydrodynamic zones.

Table 9

Comparison of this work results and literature data

\begin{tabular}{llll}
\hline Absorbent & Packing & $k_{L} a\left(\mathrm{~m} \mathrm{~s}^{-1}\right)\left(\times 10^{4}\right)$ & Reference \\
\hline PEG 400 & & $1.4-5.5$ & Cotte (1996) \\
DEHA & Hiflow rings & $2.5-24$ & This work \\
Water & & $78-83$ & Cotte (1996) \\
\hline
\end{tabular}

liquid and gas phases are small. In the loading zone, changing the gas velocity from 0.42 to 1.50 increases the $k_{L} a$ value from $0.3 \times 10^{-3}$ to $2.4 \times 10^{-3} \mathrm{~s}^{-1}$. The gas interaction with the liquid can also be observed by considering the liquid hold-up.

It is interesting to compare the $k_{L} a$ values obtained with data from other literature (Table 9). With the same packing (Hiflow rings), it appears that DEHA occupies an intermediate position between PEG 400 and water. DEHA is thus more effective than PEG 400 for absorbing toluene.

4.2.2.3. Modelling of experimental results. Onda and Billet proposed correlations to model the wetted area $a_{w}$. The predictions of these authors differ considerably. This big difference results from developments in packing systems between 1968 and 1993. The higher void fraction and improved shapes have enabled modern packing systems to provide much more extensive interfacial areas due to the numerous droplets and trickles. Billet's correlation, established using more recent packing systems, is thus more appropriate for the packing used in this study.

Table 10 compares the predictions of Onda and Billet with the experimental results. Onda's simple-to-use correlations give values very far from the experimental results, which is to be expected given the above explanation. Billet's more recent correlations give predictions that are closer to reality but still too inaccurate and therefore not valid for industrial utilisation. This inaccuracy can be explained by the fact that the viscosity of DEHA does not fall within the range of values used by Billet to adjust his correlations. Table 11 summarises the ranges of experimental operating parameters used by Billet and by this study: it shows that our experimental data are included within the values investigated by Billet et al., except that the kinetic viscosity of DEHA is much higher than that of the liquids used by Billet. Therefore, this explains the predictions of the Billet correlation, which overestimate the liquid-side mass transfer coefficients by a factor of 10-50.

The two correlations from the literature are not satisfactory for modelling our system. Analysis of experimental data shows that the $k_{L} a$ varies versus the gas velocity and rather little in function of liquid velocity. This observation is not much described in the literature. In fact, most authors agree in describing mass transfer as a value dependent on the liquid velocity and independent of the gas velocity. This is the case of the Billet and Onda relationships used in this work. Nonetheless, this unexpected behaviour of our system has also been observed by two recent authors. Cotte (1996) used PEG $400(\mu=80 \mathrm{mPa}$ s) to absorb various VOCs (acetone, toluene, dichloromethane) and observed that the $k_{L} a$ values deduced from his experiments obeyed the law $k_{L} a=7.5 \times 10^{-4} U_{G}+5.4 \times 10^{-5}$. Cotte did not vary the liquid flow rate in his experiments and therefore did not take that parameter into account. Delaloye (1991) studied aqueous solutions with algynate, glycerol or PEG 3000 added to produce solutions whose viscosity reached $9.63 \mathrm{mPas}$. He noted two interesting phenomena. The first result he highlighted is that the gas velocity has an influence on the $k_{L} a$ in the loading zone, contrary to previously published studies. The second observation is that an increase of the viscosity leads to a reduction of the liquid velocity's influence. He showed that the

Table 10

Comparison of Billet and Onda predictions versus experimental data

\begin{tabular}{|c|c|c|c|c|c|c|}
\hline $\begin{array}{l}\text { Experiment } \\
\text { number }\end{array}$ & $\begin{array}{l}\text { Toluene in gas feed } \\
\left(\mathrm{g} \mathrm{m}^{-3}\right)\end{array}$ & $\begin{array}{l}\text { Liquid velocity } \\
\left(\mathrm{m} \mathrm{s}^{-1}\right)\end{array}$ & $\begin{array}{l}\text { Gas velocity } \\
k_{L} a\left(\mathrm{~s}^{-1}\right)\end{array}$ & $\begin{array}{l}\text { Experimental } \\
\left(\mathrm{m} \mathrm{s}^{-1}\right)\end{array}$ & $\begin{array}{l}\text { Billet } \\
k_{L} a\left(\mathrm{~s}^{-1}\right)\end{array}$ & $\begin{array}{l}\text { Onda } \\
k_{L} a\left(\mathrm{~s}^{-1}\right)\end{array}$ \\
\hline 1 & 4.990 & 0.014 & 0.422 & $2.5 \times 10^{-4}$ & $5.0 \times 10^{-2}$ & $6.4 \times 10^{-1}$ \\
\hline 2 & 1.205 & 0.014 & 0.422 & $2.5 \times 10^{-4}$ & $5.0 \times 10^{-2}$ & $6.4 \times 10^{-1}$ \\
\hline 3 & 1.193 & 0.011 & 0.422 & $3.7 \times 10^{-4}$ & $4.1 \times 10^{-2}$ & $5.4 \times 10^{-1}$ \\
\hline 4 & 5.038 & 0.007 & 0.422 & $3.2 \times 10^{-4}$ & $3.0 \times 10^{-2}$ & $4.2 \times 10^{-1}$ \\
\hline 5 & 0.520 & 0.007 & 0.964 & $2.3 \times 10^{-3}$ & $3.0 \times 10^{-2}$ & $4.2 \times 10^{-1}$ \\
\hline 6 & 1.005 & 0.007 & 1.005 & $2.4 \times 10^{-3}$ & $3.0 \times 10^{-2}$ & $4.2 \times 10^{-1}$ \\
\hline 7 & 1.005 & 0.007 & 1.502 & $2.4 \times 10^{-3}$ & $3.0 \times 10^{-2}$ & $4.2 \times 10^{-1}$ \\
\hline
\end{tabular}


Table 11

Parameters ranges of Billet's work and this work

\begin{tabular}{|c|c|c|}
\hline Variable & $\begin{array}{l}\text { Range investigated by Billet (1990) and } \\
\text { Billet and Schultes (1991, 1992) }\end{array}$ & Range investigated in this work \\
\hline Gas capacity factor $F_{G}\left(\mathrm{~Pa}^{1 / 2}\right)$ & $0.003-2.77$ & $0.510-2.18$ \\
\hline Superficial liquid velocity $U_{L}\left(\mathrm{~m} \mathrm{~s}^{-1}\right)\left(\times 10^{3}\right)$ & $0.071-32.77$ & $4.24-14.1$ \\
\hline Liquid density $\rho_{L}\left(\mathrm{~kg} \mathrm{~m}^{-3}\right)$ & $361-1237$ & 930 \\
\hline Liquid kinetic viscosity $v_{L}\left(\mathrm{~m}^{2} \mathrm{~s}^{-1}\right)\left(\times 10^{6}\right)$ & $0.14-1.66$ & 15.5 \\
\hline Diffusion coefficient ${ }^{\mathrm{a}} D_{L}\left(\mathrm{~m}^{2} \mathrm{~s}^{-1}\right)\left(\times 10^{-9}\right)$ & $0.29-6.50$ & 0.86 \\
\hline Superficial tension $\sigma_{L}\left(N \mathrm{~m}^{-1}\right)\left(\times 10^{3}\right)$ & $0.7-74.0$ & 31 \\
\hline Gas density $\rho_{G}\left(\mathrm{~kg} \mathrm{~m}^{-3}\right)$ & $0.07-97$ & 1.18 \\
\hline Gas diffusion coefficient ${ }^{\mathrm{a}} D_{G}\left(\mathrm{~m}^{2} \mathrm{~s}^{-1}\right)\left(\times 10^{6}\right)$ & $0.29-87.4$ & 7.6 \\
\hline Gas dynamic viscosity $\mu_{G}(\mathrm{Pas})\left(\times 10^{6}\right)$ & $0.14-126$ & 15.4 \\
\hline
\end{tabular}

${ }^{a}$ Diffusion coefficient of toluene into the considered liquid.

exponent of the $U_{L}$ term decreases as the viscosity increases. All these observations show the lack of knowledge regarding the modelling of mass transfer in viscous systems. Complementary work is needed to be carried out in order to provide a correlation that enables accurate prediction of the results.

\section{Conclusion}

This study examined hydrodynamics and mass transfer of a packed column fed with DEHA to remove the toluene from a medium-concentration gaseous effluent $\left(0.5-5 \mathrm{~g} \mathrm{~m}^{-3}\right)$.

The hydrodynamic study showed that the viscosity of DEHA was not a technical obstacle to its implementation in an industrial column. The pressure drops caused remain within acceptable levels. From a modelling point of view, the bibliographical summary dealt with numerous works and described the more recent of them. The correlations given proved satisfactory for the prediction of hydrodynamic values (dry column pressure drops, liquid hold-up, wet column pressure drops). We recommend using the correlations proposed by Billet because they are accurate and quite simple to use.

The study of the absorption of toluene by DEHA showed the efficiency of this process (initial toluene recovery performance close to $100 \%$ under our experimental conditions). Nonetheless, this efficiency decreases quickly when the washing liquid becomes loaded with toluene. An effective regeneration process is therefore essential in order to make the process technically viable.

Concerning mass transfer modelling, the mass transfer is supposed to be limited by the liquid-side resistance, which seems logical since DEHA is a viscous absorbent. The bibliographical review showed that few recent works have been devoted to the modelling of gas-liquid mass transfer in packed columns. Billet and Schultes (1999) is the only author to have recently tried elaborating a new theory for predicting mass transfer coefficients. He based his model on a data bank created from a great deal of data from the literature, which enabled him to propose a more accurate correlation than those given in previous works. Nonetheless, few authors have investigated viscous fluids and Billet's correlations proved relatively inaccurate for predicting toluene transfer coefficients in the case of DEHA.
Our experimental results showed that the $k_{L} a$ of the system depends on the liquid velocity but also on the gas velocity. This behaviour has also been observed by the few authors who have used viscous fluids in their experiments, but is contrary to all the authors who have work on low-viscosity fluids: generally, these authors express $k_{L} a$ using a term that increases with liquid velocity and does not take into account the gas velocity. It is therefore clear that the influence of viscosity on the phenomenon is considerable and that further research is necessary in order to better describe this area of study.

This work contributes to the development of hybrid absorption-pervaporation processes for treating gases containing hydrophobic compounds. The aim of this study was to evaluate the potential of using a heavy solvent (DEHA) to absorb such compounds in a packed column and, based on a bibliographical summary, to propose empirical correlations for both determining the hydrodynamic behaviour and estimating mass transfer coefficients with a view to scaling up the system for industrial applications. It is important to note that the economic cost of the solvent is not covered in this work but was taken into consideration for the laboratory-scale tests. The recovery of hydrophobic VOCs and the regeneration of the solvent by pervaporation will be presented in a future paper.

\section{Notation}

$a \quad$ specific surface area of packing, $\mathrm{m}^{2} \mathrm{~m}^{-3}$

$a_{h} \quad$ hydraulic area, $\mathrm{m}^{2} \mathrm{~m}^{-3}$

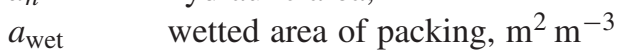

$C_{F l} \quad$ packing constant for flooding (Mackowiak, 1990)

$C_{G} \quad$ gas concentration, mol m$^{-3}$

$C_{h} \quad$ packing constant for hold-up (Billet, 1990; Billet and Schultes, 1991,1992)

$C_{L} \quad$ liquid concentration, $\mathrm{mol} \mathrm{m}^{-3}$

$C_{L}^{*}, C_{V}^{*}$ packing constant for hold-up (Billet and Schultes, 1993, 1999)

$d_{h} \quad$ hydraulic diameter, $\mathrm{m}$

$d_{p} \quad$ packing size, $\mathrm{m}$

$d_{T} \quad$ droplet size, $\mathrm{m}$ 


$\begin{array}{ll}D_{G}, D_{L} & \text { gas and liquid diffusivities, } \mathrm{m}^{2} \mathrm{~s}^{-1} \\ F_{G}, F_{L} & \text { gas or liquid capacity factor } F_{G}= \\ & \rho_{G}^{1 / 2} U_{G}, \mathrm{~kg}^{1 / 2} \mathrm{~m}^{-1 / 2} \mathrm{~s}^{-1} \\ F(S) & \text { friction factor } \\ g & \text { gravitational acceleration, } \mathrm{m} \mathrm{s}^{-2} \\ h_{L} & \text { liquid hold-up, } \mathrm{m}^{3} \mathrm{~m}^{-3} \\ h_{L}, F & \text { flooding liquid hold-up, } \mathrm{m}^{3} \mathrm{~m}^{-3} \\ h_{K}, h_{B} & \text { Kozeny and Burke-Plummer constants } \\ H & \text { Henry constant, dimensionless } \\ k & \text { hydrodynamic parameter (Takahashi) } \\ k_{G}, k_{L} & \text { partial mass transfer coefficients, } \mathrm{m} \mathrm{s}^{-1} \\ K_{p} & \text { wall factor } \\ K_{G}, K_{L} & \text { global mass transfer coefficients, } \mathrm{m} \mathrm{s}^{-1} \\ L, G & \text { specific liquid or gas flow rates, } \mathrm{kg} \mathrm{m}^{-2} \mathrm{~s}^{-1} \\ Q_{G}, Q_{L} & \text { gas or liquid flow rate, } \mathrm{m}^{3} \mathrm{~h}^{-1} \\ S & \text { column section, } \mathrm{m}^{2} \\ t & \text { time, h } \\ U & \text { superficial liquid velocity, } \mathrm{m} \mathrm{s}^{-1} \\ V_{C} & \text { column volume, } \mathrm{m}^{3} \\ x, y & \text { liquid or gas mass fraction } \\ Z & \text { packing height, } \mathrm{m}\end{array}$

\section{Greek letters}

$\alpha$

$\beta$

$\Delta P_{0}$

$\Delta P_{\text {wet }}$

$\Delta P / Z$

$\varepsilon$

$\mu$

$\mu_{M}$

$\rho$

$\sigma_{c}$

$\sigma_{L}$

$\Psi_{0}$

$\Psi_{G, L}$

\section{Subscripts}

$\begin{array}{ll}F & \text { flooding } \\ G & \text { gas } \\ \text { in, out } & \text { inlet, outlet } \\ L & \text { liquid }\end{array}$

\section{Dimensionless numbers}

$C a=\frac{\mu_{L} u_{L}}{\sigma_{L}} \quad$ Capillary number of liquid

$F r=\frac{u_{G}^{2}}{g d_{0}} \quad$ Froude number of gas

$M=\frac{g \mu_{L}^{4}}{\rho_{L} \sigma_{L}^{3}} \quad$ Morton number of liquid

$\operatorname{Re}_{G}=\frac{U_{G} \rho_{G}}{\mu_{G} a} \quad$ Reynolds number of gas
$R e_{L}=\frac{U_{L} \rho_{L}}{\mu_{L} a} \quad$ Reynolds number of liquid
$S c=\frac{\mu}{\rho D_{L}} \quad$ Schmidt number of liquid
$S h=\frac{d_{h}}{\delta} \quad$ Sherwood number
$W e_{L}=\frac{\rho_{L} U_{L}^{2}}{\sigma_{L} a} \quad$ Weber number of liquid

\section{Acknowledgements}

This work was carried out with the financial support of the ADEME (Agence de l'Environnement et de la Maitrise de l'Energie, France) and the Europe Environnement company (Vieux Thann, France).

\section{References}

Billet, R., 1990. Contribution to design and scale up of packed columns. Fat Science and Technology 9, 361-370.

Billet, R., Schultes, M., 1991. Modelling of pressure drop in packed columns. Chemical Engineering and Technology 14 (2), 89-95.

Billet, R., Schultes, M., 1992. Relation between pressure drop and masstransfer in two-phase countercurrent-flow columns. Fat Science and Technology 4 (94), 138-144.

Billet, R., Schultes, M., 1993. Predicting mass transfer in packed columns. Chemical Engineering and Technology 16, 1-9.

Billet, R., Schultes, M., 1995. Influence of phase ratio on packing efficiency in columns for mass transfer processes. Chinese Journal of Chemical of Engineering 5 (2), 117-126.

Billet, R., Schultes, M., 1999. Prediction of mass transfer columns with dumped and arranged packings. Transactions of the Institution of Chemical Engineers 77, 498-504.

Cotte, F., 1996. Absorption en colonne garnie et en tour à atomisation. Application au traitement de composés organiques volatils. Thesis, Université de Pau et des Pays de l'Adour, Alès.

Delaloye, M., 1991. The influence of viscosity on the liquid-phase mass transfer resistance in packed columns. Chemical Engineering Journal 47, 51-61.

Heymes, F., Manno-Demoustier, P., Charbit, F., Fanlo, J.L., Moulin, P., 2006. A new efficient absorption liquid to treat exhaust air loaded with toluene. Chemical Engineering Journal 115 (3), 225-231.

Iliuta, I., Grandjean, B.P.A., Piché, S., Larachi, F., 2003. Two fluid model for counter-current dumped packing-containing columns. Chemical Engineering Science 58, 1373-1380.

Leva, M., 1992. Reconsider packed-tower pressure-drop correlations. Chemical Engineering Progress 65-72.

Mackowiak, J., 1990. Determination of flooding gas velocity and liquid hold-up at flooding in packed columns for gas/liquid systems. Chemical Engineering and Technology 13, 184-196.

Mackowiak, J., 1991. Pressure drop in irrigated packed columns. Chemical Engineering Progress 29, 93-105.

Miyahara, T., Ogawa, K., Hirade, A., Takahashi, T., 1992. Flow dynamics in low height packed columns having large fractional void space. Chemical Engineering Science 47 (13/14), 3323-3330.

Onda, U., Takeuchi, H., Okumoto, Y., 1968. Mass transfer coefficients between gas and liquid phases in packed columns. Journal of Chemical Engineering of Japan 1 (56),

Piché, S., Iliuta, I., Grandjean, B.P.A., Larachi, F., 2001. A unified approach to hydraulics and mass transfer in randomly packed towers. Chemical Engineering Science 56, 6003-6013.

Takahashi, T., Akagi, Y., Ueyama, K., 1979. A new correlation for pressure drop in packed columns. Journal of Chemical Engineering of Japan 12 (5), 341-346. 